\title{
What can we learn from long-term studies on chronic low back pain? A scoping review
}

\author{
Alisa L. Dutmer ${ }^{1}(\mathbb{D}) \cdot$ Remko Soer $^{1,2,3} \cdot$ André P. Wolff $^{3,4}\left(\mathbb{D} \cdot\right.$ Michiel F. Reneman $^{1}\left(\mathbb{D} \cdot\right.$ Maarten H. Coppes $^{5}$. \\ Henrica R. Schiphorst Preuper ${ }^{1,3}$ [D
}

Received: 9 June 2021 / Revised: 22 December 2021 / Accepted: 5 January 2022 / Published online: 19 January 2022

(C) The Author(s) 2022

\begin{abstract}
Purpose A scoping review was conducted with the objective to identify and map the available evidence from long-term studies on chronic non-specific low back pain (LBP), to examine how these studies are conducted, and to address potential knowledge gaps.

Method We searched MEDLINE and EMBASE up to march 2021, not restricted by date or language. Experimental and observational study types were included. Inclusion criteria were: participants between 18 and 65 years old with non-specific sub-acute or chronic LBP, minimum average follow-up of $>2$ years, and studies had to report at least one of the following outcome measures: disability, quality of life, work participation, or health care utilization. Methodological quality was assessed using the Effective Public Health Practice Project quality assessment. Data were extracted, tabulated, and reported thematically.

Results Ninety studies met the inclusion criteria. Studies examined invasive treatments (72\%), conservative (21\%), or a comparison of both (7\%). No natural cohorts were included. Methodological quality was weak (16\% of studies), moderate $(63 \%)$, or strong (21\%) and generally improved after 2010. Disability (92\%) and pain (86\%) outcomes were most commonly reported, followed by work (25\%), quality of life (15\%), and health care utilization (4\%). Most studies reported significant improvement at long-term follow-up (median 51 months, range 26 months-18 years). Only 10 (11\%) studies took more than one measurement $>2$ year after baseline.

Conclusion Patients with persistent non-specific LBP seem to experience improvement in pain, disability and quality of life years after seeking treatment. However, it remains unclear what factors might have influenced these improvements, and whether they are treatment-related. Studies varied greatly in design, patient population, and methods of data collection. There is still little insight into the long-term natural course of LBP. Additionally, few studies perform repeated measurements during long-term follow-up or report on patient-centered outcomes other than pain or disability.
\end{abstract}

Keywords Scoping review $\cdot$ Chronic low back pain $\cdot$ Long-term follow-up · Disability · Quality of life $\cdot$ Work participation

Michiel F. Reneman

m.f.reneman@umcg.nl

1 Department of Rehabilitation, University Medical Center Groningen, University of Groningen, Groningen, The Netherlands

2 Expertise Center of Health and Movement, Saxion University of Applied Sciences, Enschede, The Netherlands

3 University Medical Center Groningen, Pain Center, University of Groningen, Groningen, The Netherlands
4 Department of Anesthesiologie, University Medical Center Groningen, University of Groningen, Groningen, The Netherlands

5 Department of Neurosurgery, University Medical Center Groningen, University of Groningen, Groningen, The Netherlands 


\section{Introduction}

Low back pain (LBP) is very common and poses a great health risk for society. Worldwide, it is the number one cause of years lived with disability [1]. Up to $84 \%$ of the population will experience LBP at least once during their lifetime [2]. In roughly $90 \%$ of cases, a specific source for the LBP cannot be identified [3]. LBP is strongly associated with disability [1, 4], work absence [5, 6], and reduced quality of life $[6,7]$. As a result, medical and particularly non-medical costs related to LBP are very high $[8,9]$.

Most patients improve substantially in the first six weeks after the onset of LBP [10]. However, one year after onset, approximately two thirds of patients still experience pain and disability [10-12]. Currently, LBP is looked at more and more as a long-lasting or recurrent condition rather than a series of unrelated episodes $[9,13]$. A review on the long-term course (follow-up ranged from one to 28 years) of LBP in the general population found that most patients experienced a somewhat stable or fluctuating occurrence of LBP over time [14]. Becoming pain free was never reported as a common finding.

Despite the effects of LBP on physical, psychological, and social well-being, there are few longitudinal studies reporting multiple patient-centered outcomes. Cohort studies with long-term follow-up ( $>2$ years) often confine to investigating the presence of pain (yes/no) or the number of days with pain over the past month(s) or year [13, 14]. Several consensus statements have been published on outcome measures in chronic (back) pain research [15-17]. Most reports specifically provide recommendations for the evaluation of clinical trials, but there is an overall understanding that reporting on pain alone in LBP research is insufficient. Other important outcome domains include measures of physical function, generic measures of health and well-being, quality of life, and work (dis)ability.

At present, it is unclear what evidence is available from long-term studies on chronic non-specific LBP. More specifically, from studies examining patient-centered outcomes other than pain. We conducted a scoping review with the objective to identify and map the available evidence from studies on chronic LBP with long-term follow-up, to examine how these studies are conducted, and to address potential knowledge gaps. Where systematic reviews typically focus on more narrow and welldefined questions with appropriate study designs chosen in advance, a scoping review tends to address broader topics where many different study designs might be applicable [18]. For the present study, we included experimental and observational studies reporting at least two-year follow-up on disability, quality of life, work participation or health care utilization in patients with chronic non-specific LBP. The results are not intended to provide evidence to inform clinical practice, but rather to gain insight into the scientific literature that is currently available. For studying the feasibility, appropriateness or effectiveness of a certain treatment or practice, a systematic review is a more valid approach [19].

\section{Methods}

The PRISMA Extension for scoping reviews (PRISMA$\mathrm{ScR}$ ) was used as a reporting guideline for this review [20]. Although critical appraisal is optional, for the present study we evaluated methodological quality of the included studies with a quality assessment tool in order to be able to address any potential gaps in the literature related to low quality of research [21].

\section{Eligibility criteria}

\section{Types of studies}

Both experimental and observational studies investigating non-specific LBP with baseline measures and a minimum (mean) follow-up of $>2$ years were included. Case reports and review studies were excluded.

\section{Participants}

Study participants were adults with sub-acute (6-12 weeks) or chronic (>12 weeks) non-specific low back pain at study baseline, with or without leg pain. The average age of the study population had to be between 18 and 65 years. Studies that reported on LBP due to a specified physical cause (e.g., infection, tumor, osteoporosis, fracture, structural deformity, inflammatory disorder, radicular syndrome or cauda equina syndrome) were excluded. Studies on patients with LBP due to failed back surgery syndrome (FBSS) and LBP due to degenerative changes such as disk degeneration, osteoarthritis of facet joints, and a grade 1 degenerative spondylolisthesis were included, provided that there were no neurological symptoms. Little to no association has been found between imaging findings of these types of spine degeneration and the presence of LBP [22-26]. We therefore classified these (radiological) diagnoses as non-specific. Studies with mixed LBP groups (specific and non-specific cause for LBP) or mixed pain populations (e.g., neck pain and LBP) were excluded unless subgroup data for baseline and follow-up were presented. 


\section{Outcome measures}

To be included, studies had to report on at least one of the following outcome measures: disability, quality of life, work participation, or health care utilization. Pain was also an outcome measure, but studies that only reported on pain were not included.

\section{Search methods for identification of studies}

Electronic searches in MEDLINE and EMBASE were conducted using indexed terms and free text words. The searches were not restricted by date, language, or place of publication. The search strategy included terms related to LBP, long-term follow-up and outcome measures (Supplementary Digital Content [SDC] 1). The search results for both databases were downloaded into RefWorks and duplicates were removed. An initial literature search was performed, followed by several updates, of which the last took place on March 5 2021. Initially, search terms for spondylolysis and spondylolisthesis were included. However, these were removed in the updated searches. We found that studies that were retrieved with these search terms (and that would not have been retrieved by searching for terms related to low back pain) targeted patients with spondylolisthesis with a higher than grade 1 degree of severity.

\section{Data collection and analysis}

\section{Study selection}

Three review authors independently screened titles, abstracts, and full text of the studies retrieved from the databases. One author (AD) screened all studies and two authors (RS, RSP) each screened half. The inclusion criteria included type of participants, length of follow up, and outcome measures. To determine interrater agreement, a sample of 200 studies was selected for the three reviewers to screen on title, abstract and full text. Agreement ranged from 98 to 99\% between reviewers with kappa scores ranging 0.56-0.98 (moderate or substantial agreement). However, kappa scores are deemed not very reliable for 'rare findings' [27] and in this sample of 200 studies ultimately only 3 studies were included after consensus was reached. Any disagreement in the selection of studies was discussed until consensus was reached. If the three reviewers could not reach consensus, the fourth reviewer (MR) was consulted.

\section{Quality assessment}

The Effective Public Health Practice Project Quality Assessment Tool (EPHPP) was used to evaluate methodological quality of the studies [28]. The tool can be used to evaluate a variety of study designs such as RCTs, observational, cross sectional, and before-and-after studies. The EPHPP assesses six domains: (1) selection bias, (2) study design, (3) confounders, (4) blinding, (5) data collection method, and (6) withdrawals and dropouts. Each domain can be rated strong, moderate, or weak resulting in a global rating of strong (no weak ratings), moderate (one weak rating), or weak (two or more weak ratings) for each study. The confounders domain was scored 'not applicable' when there was no comparison or control group, since the corresponding question was phrased "Were there important differences between groups prior to the intervention?". Content and construct validity of the EPHPP have been established and inter-rater reliability is fair for the individual domains ( $\mathrm{ICC}=0.60$ ) and excellent for the global rating $(\mathrm{ICC}=0.77)[28,29]$. Four reviewers assessed methodological quality of the studies. One author (AD) assessed all studies and three authors (RS, RSP, MR) each assessed one third of the studies. Disagreements were resolved between the authors assessing the study or when in doubt were discussed with all four assessing authors to reach consensus.

\section{Data extraction and synthesis}

The following data were extracted by one author (AD) from each paper and presented in supplementary tables (SDC 2): first author, study setting and country, study design, intervention(s), patient characteristics (diagnoses, age, $\%$ female), outcome domain(s), instrument(s), duration of follow-up, and results of measurements taken at baseline and $>2$ year follow-up. This includes the results of any responder analyses (i.e., the proportion of patients achieving a pre-defined level of improvement) [30]. For randomized controlled trials (RCT), results from the intention-to-treat analyses were reported. Studies were organized thematically according to intervention type. Study characteristics were also summarized in a narrative format and the overall findings were presented in a summary table. Per outcome, the number of treatment arms that showed a significant $(p<0.05)$ improvement, decline, or no change compared to baseline was reported. The number of studies that did not report p-values for the change in outcome at follow-up was also reported.

\section{Results}

\section{Study selection}

Together, the initial and updated searches returned 10,312 articles, of which 90 ultimately met the inclusion criteria (Fig. 1). Follow-up results of one study were presented in two different articles [31,32]. An overview of study 


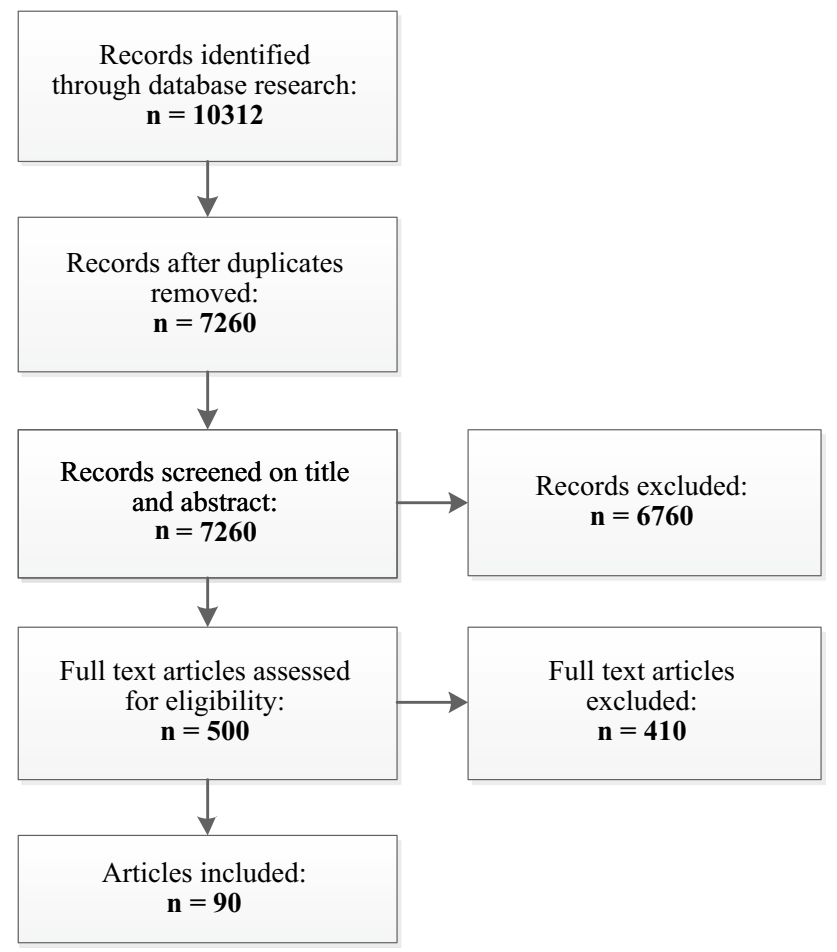

Fig. 1 Flow chart of the literature search

characteristics can be found in SDC 2. Studies $(n=89)$ were classified according to the type of treatment(s) that was investigated: invasive (72\%, $n=64$; Table 1 , SDC 2), conservative $(21 \%, n=19$; Table 2 , SDC 2$)$, or a comparison of invasive and conservative treatments $(7 \%, n=6$; Table 3 , SDC 2). By definition, (minimal) invasive procedures require (1) a method of access to the body (incision, natural orifice, or percutaneous access), (2) instrumentation (e.g., endoscopes, catheters, scalpels), and (3) requirement for operator skill [33]. All non-invasive treatments were classified under conservative treatments.

\section{Quality assessment}

Global quality rating was weak for $14(16 \%)$, moderate for $56(63 \%)$, and strong for 19 (21\%) studies (Table 1). A global weak rating was more common with studies published before 2010, while most studies that rated strong were published in the last decade (Fig. 2). Most common design was either a prospective $(44 \%, n=39)$ or retrospective cohort study $(31 \%, n=28)$ (both rated 'moderate'). Twenty-one studies (24\%) conducted an RCT and one study was classified as a controlled clinical trial [34] (both rated 'strong'). Weak ratings were prevalent with the domain 'selection bias', while strong ratings were prevalent for 'data collection method'. Studies rated predominantly moderate $(42 \%, n=37)$ or strong $(44 \%, n=39)$ on 'withdrawals and dropouts'. Sixty studies (67\%) did not receive a rating on 'confounders' due to the absence of a comparison or control group. Twenty-six (29\%) retrospective studies received a 'moderate' rating for scoring 'not applicable' on the item 'percentage of patients completing the study'.

\section{Study Characteristics}

\section{Year published}

Studies were published between 1985 and 2021, with 52 out of 89 studies (58\%) published in the last decade (Fig. 2).

\section{Study Setting}

The majority of selected studies $(83 \%, n=74)$ were from Western countries (SDC 2). More specifically, from European countries $(54 \%, n=48)$, such as Germany $(10 \%, n=8)$, Sweden, the UK (both 9\%, $n=7$ ), Norway, the Netherlands (both $8 \%, n=7)$, and from the USA $(27 \%, n=24)$. Thirteen studies $(15 \%)$ were from Asian countries of which seven (8\%) from China. Two studies were from Brazil (2\%). There were no studies from African countries, Central America, or Eastern Europe.

Less than half of the selected studies $(44 \%, n=39)$ specified the setting in which they took place. Forty-six out of 64 studies on invasive treatments did not report or were unclear in their report on where a specific intervention took place. The 18 remaining studies (20\%) specified they took place in (university) hospitals or (out-patient) medical practices. Studies on conservative treatments mostly took place in (university) hospitals, physiotherapy clinics, and chiropractic and general practices. Five out of six studies that compared invasive with conservative treatments took place in university hospitals.

\section{Interventions}

Most common types of invasive treatment were lumbar fusion (38\% of studies, $n=34)$ and disc arthroplasty $(25 \%$, $n=22$ ), followed by intradiscal therapies (e.g., intradiscal electrothermal therapy or intradiscal bone marrow injection; $11 \%, n=10$ ), and implantable therapies (e.g., spinal cord stimulation) $[35,55,86]$ (SDC 2). Less common were interspinous process devices [39, 63], dynamic spine stabilization systems [57, 85], and basivertebral nerve ablation [48]. Two studies used sham infiltration as a control for intradiscal bone marrow injection $[36,70]$.

Most common conservative treatments were multidisciplinary treatment ( $10 \%$ of studies, $n=9$ ), physiotherapy or exercise training $(7 \%, n=6)$, cognitive therapies $(4 \%$, $n=4)$, advice and/or education $(4 \%, n=4)$. Other treatments consisted of (non-operative) care as usual [108, 112, 121] 
Table 1 EPHPP quality assessment scores of the included studies

\begin{tabular}{|c|c|c|c|c|c|c|c|}
\hline \multirow[t]{2}{*}{ References } & \multicolumn{7}{|l|}{ EPHPP domain } \\
\hline & Selection bias & Study design & Confounders & Blinding & $\begin{array}{l}\text { Data collec- } \\
\text { tion method }\end{array}$ & $\begin{array}{l}\text { Withdrawals } \\
\text { and dropouts }\end{array}$ & Global rating \\
\hline \multicolumn{8}{|l|}{ Studies on invasive treatments } \\
\hline Al-Kaisy et al. [35] & M & M & $\mathrm{n} / \mathrm{a}$ & $\mathrm{M}$ & $\mathrm{S}$ & $S$ & Strong \\
\hline Amirdelfan et al. [36] & M & S & $\mathrm{W}$ & M & S & M & Moderate \\
\hline Aunoble et al. [37] & M & M & $\mathrm{n} / \mathrm{a}$ & M & $S$ & $S$ & Strong \\
\hline Axelsson et al. [38] & $\mathrm{W}$ & M & $\mathrm{n} / \mathrm{a}$ & M & W & M & Weak \\
\hline Buric and Pulidori [39] & $\mathrm{W}$ & M & $\mathrm{n} / \mathrm{a}$ & M & $\mathrm{S}$ & $\mathrm{S}$ & Moderate \\
\hline Burkus et al. [40] & M & M & $\mathrm{W}$ & M & $S$ & W & Weak \\
\hline $\begin{array}{l}\text { Buttermann and Mullin [31] } \\
\text { and Butterman et al. [32] }\end{array}$ & $\mathrm{W}$ & M & $\mathrm{S}$ & M & $\mathrm{S}$ & S & Moderate \\
\hline Buttermann et al. [41] & M & $\mathrm{S}$ & S & $S$ & $S$ & $S$ & Strong \\
\hline Cakir et al. [42] & $\mathrm{W}$ & M & $\mathrm{n} / \mathrm{a}$ & M & S & M & Moderate \\
\hline Cheng et al. [43] & $\mathrm{W}$ & M & $\mathrm{n} / \mathrm{a}$ & M & S & S & Moderate \\
\hline Cheng et al. [44] & M & M & $\mathrm{n} / \mathrm{a}$ & M & $S$ & M & Strong \\
\hline Chung et al. [45] & $\mathrm{W}$ & S & $\mathrm{S}$ & M & S & $\mathrm{S}$ & Moderate \\
\hline Corenman et al. [46] & $\mathrm{W}$ & M & $\mathrm{n} / \mathrm{a}$ & M & S & M & Moderate \\
\hline Di Silvestre et al. [47] & $\mathrm{W}$ & M & $\mathrm{S}$ & M & S & M & Moderate \\
\hline Fischgrund et al. [48] & $\mathrm{W}$ & M & $\mathrm{n} / \mathrm{a}$ & M & S & $\mathrm{S}$ & Moderate \\
\hline Formica et al. [49] & $\mathrm{W}$ & M & $\mathrm{n} / \mathrm{a}$ & M & $S$ & M & Moderate \\
\hline Geerdes et al. [50] & $\mathrm{W}$ & M & $\mathrm{n} / \mathrm{a}$ & M & $S$ & M & Moderate \\
\hline Gepstein et al. [51] & W & M & $\mathrm{n} / \mathrm{a}$ & M & $S$ & $S$ & Moderate \\
\hline Gioia et al. [52] & $\mathrm{W}$ & M & $\mathrm{n} / \mathrm{a}$ & M & $S$ & W & Weak \\
\hline Gornet et al. [53] & M & $\mathrm{S}$ & $\mathrm{S}$ & M & S & M & Strong \\
\hline Guyer et al. [54] & M & $S$ & $S$ & M & S & $\mathrm{W}$ & Moderate \\
\hline Hamm-Faber et al. [55] & $\mathrm{W}$ & M & $\mathrm{n} / \mathrm{a}$ & M & $\mathrm{S}$ & $\mathrm{S}$ & Moderate \\
\hline Houten et al. [56] & M & M & $\mathrm{n} / \mathrm{a}$ & M & W & $\mathrm{W}$ & Weak \\
\hline Kareem and Ulbricht [57] & M & M & $\mathrm{n} / \mathrm{a}$ & M & S & $\mathrm{W}$ & Moderate \\
\hline Katsimihas et al. [58] & $\mathrm{W}$ & M & $\mathrm{n} / \mathrm{a}$ & $\mathrm{W}$ & S & $\mathrm{M}^{\mathrm{a}}$ & Weak \\
\hline Kuslich et al. [59] & $\mathrm{W}$ & M & $\mathrm{n} / \mathrm{a}$ & M & $\mathrm{W}$ & S & Moderate \\
\hline Lee et al. [60] & M & M & $\mathrm{n} / \mathrm{a}$ & M & $\mathrm{S}$ & $S$ & Strong \\
\hline Liang et al. [61] & W & M & $\mathrm{n} / \mathrm{a}$ & M & $S$ & M & Moderate \\
\hline Lu et al. [62] & $\mathrm{W}$ & M & $\mathrm{n} / \mathrm{a}$ & M & $S$ & $S$ & Moderate \\
\hline Lu et al. [63] & $\mathrm{W}$ & M & $\mathrm{n} / \mathrm{a}$ & M & S & M & Moderate \\
\hline Madan and Boeree [64] & $\mathrm{W}$ & M & $\mathrm{n} / \mathrm{a}$ & M & $S$ & M & Moderate \\
\hline Madan et al. [65] & $\mathrm{W}$ & M & S & M & $S$ & M & Moderate \\
\hline Maestretti et al. [66] & $\mathrm{W}$ & M & $\mathrm{n} / \mathrm{a}$ & M & S & $S$ & Moderate \\
\hline Malham and Parker et al. [67] & M & M & $\mathrm{n} / \mathrm{a}$ & M & $S$ & $S$ & Strong \\
\hline Meir et al. [68] & $\mathrm{W}$ & M & $\mathrm{n} / \mathrm{a}$ & M & S & S & Moderate \\
\hline Niemeyer et al. [69] & $\mathrm{W}$ & M & $\mathrm{n} / \mathrm{a}$ & M & S & M & Moderate \\
\hline Noriega et al. [70] & W & $S$ & $\mathrm{~W}$ & $\mathrm{~S}$ & S & S & Weak \\
\hline Nunley et al. [71] & M & M & $\mathrm{n} / \mathrm{a}$ & M & $S$ & W & Moderate \\
\hline Nystrom et al. [72] & M & M & $\mathrm{n} / \mathrm{a}$ & M & $S$ & $S$ & Strong \\
\hline Ohtori et al. [73] & $\mathrm{W}$ & $\mathrm{S}$ & S & M & S & $\mathrm{W}$ & Weak \\
\hline Pan et al. [74] & M & M & $\mathrm{n} / \mathrm{a}$ & M & $S$ & $S$ & Strong \\
\hline Park et al. [75] & $\mathrm{W}$ & M & $\mathrm{n} / \mathrm{a}$ & M & S & M & Moderate \\
\hline Park et al. [76] & W & M & $\mathrm{n} / \mathrm{a}$ & M & $S$ & M & Moderate \\
\hline Peng et al. [77] & W & M & $\mathrm{n} / \mathrm{a}$ & M & S & M & Moderate \\
\hline Petilon et al. [78] & $\mathrm{W}$ & M & $\mathrm{n} / \mathrm{a}$ & M & S & M & Moderate \\
\hline Pettine et al. [79] & M & M & $\mathrm{n} / \mathrm{a}$ & M & $\mathrm{S}$ & $\mathrm{S}$ & Strong \\
\hline
\end{tabular}


Table 1 (continued)

\begin{tabular}{|c|c|c|c|c|c|c|c|}
\hline \multirow[t]{2}{*}{ References } & \multicolumn{7}{|c|}{ EPHPP domain } \\
\hline & Selection bias & Study design & Confounders & Blinding & $\begin{array}{l}\text { Data collec- } \\
\text { tion method }\end{array}$ & $\begin{array}{l}\text { Withdrawals } \\
\text { and dropouts }\end{array}$ & Global rating \\
\hline Pihlajamaki et al. [80] & W & M & $\mathrm{n} / \mathrm{a}$ & M & W & M & Weak \\
\hline Pimenta et al. [81] & W & $\mathrm{S}$ & $\mathrm{S}$ & M & $\mathrm{S}$ & $\mathrm{S}$ & Moderate \\
\hline Pimenta et al. [82] & W & M & $\mathrm{n} / \mathrm{a}$ & M & $\mathrm{S}$ & $\mathrm{S}$ & Moderate \\
\hline Plais et al. [83] & W & M & $\mathrm{n} / \mathrm{a}$ & M & S & M & Moderate \\
\hline Pokorny et al. [84] & W & M & $\mathrm{n} / \mathrm{a}$ & M & S & S & Moderate \\
\hline Putzier et al. [85] & W & $\mathrm{S}$ & $\mathrm{S}$ & M & S & M & Moderate \\
\hline Raphael et al. [86] & W & M & $\mathrm{n} / \mathrm{a}$ & M & W & M & Weak \\
\hline Ren et al. [87] & W & M & $\mathrm{n} / \mathrm{a}$ & M & $\mathrm{S}$ & M & Moderate \\
\hline Rouben et al. [88] & W & M & $\mathrm{n} / \mathrm{a}$ & M & $\mathrm{S}$ & M & Moderate \\
\hline Saal and Saal [89] & W & M & $\mathrm{n} / \mathrm{a}$ & M & $S$ & $\mathrm{~S}$ & Moderate \\
\hline Schimmel et al. [90] & W & M & $\mathrm{n} / \mathrm{a}$ & M & $S$ & M & Moderate \\
\hline Schulte et al. [91] & W & M & $\mathrm{n} / \mathrm{a}$ & M & $\mathrm{S}$ & M & Moderate \\
\hline Siepe et al. [92] & W & M & $\mathrm{n} / \mathrm{a}$ & M & $\mathrm{S}$ & $\mathrm{S}$ & Moderate \\
\hline Sköld et al. [93] & M & $\mathrm{S}$ & W & M & $\mathrm{S}$ & S & Moderate \\
\hline Strube et al. [94] & W & M & $\mathrm{n} / \mathrm{a}$ & M & $S$ & M & Moderate \\
\hline Thalgott et al. [95] & W & M & $\mathrm{n} / \mathrm{a}$ & M & $S$ & M & Moderate \\
\hline Wuertinger et al. [96] & W & M & $\mathrm{n} / \mathrm{a}$ & M & S & W & Weak \\
\hline Zeilstra et al. [97] & W & M & $\mathrm{n} / \mathrm{a}$ & M & $\mathrm{S}$ & W & Weak \\
\hline \multicolumn{8}{|c|}{ Studies on conservative treatments } \\
\hline Bendix et al. [98] & M & $\mathrm{S}$ & M & M & W & M & Moderate \\
\hline Bentsen et al. [99] & $\mathrm{W}$ & $S$ & $\mathrm{~W}$ & M & W & $\mathrm{S}$ & Weak \\
\hline Carvalho et al. [100] & $\mathrm{W}$ & M & $\mathrm{n} / \mathrm{a}$ & M & $\mathrm{S}$ & $\mathrm{S}$ & Moderate \\
\hline Groot et al. [101] & $\mathrm{W}$ & M & $\mathrm{n} / \mathrm{a}$ & M & $\mathrm{S}$ & $\mathrm{S}$ & Moderate \\
\hline Haas et al. [102] & M & M & $\mathrm{S}$ & M & S & $\mathrm{W}$ & Moderate \\
\hline Hamre et al. [103] & $\mathrm{S}$ & M & $\mathrm{n} / \mathrm{a}$ & M & $\mathrm{S}$ & M & Strong \\
\hline Indahl et al. [34] & M & S & $\mathrm{S}$ & M & $S$ & $\mathrm{~S}$ & Strong \\
\hline Lamb et al. [104] & M & $\mathrm{S}$ & $\mathrm{S}$ & M & $S$ & $\mathrm{~W}$ & Moderate \\
\hline Lanes et al. [105] & $\mathrm{W}$ & M & $\mathrm{n} / \mathrm{a}$ & M & W & M & Weak \\
\hline Lankhorst et al. [106] & W & M & $\mathrm{n} / \mathrm{a}$ & M & $\mathrm{S}$ & M & Moderate \\
\hline Patrick et al. [107] & $\mathrm{S}$ & M & $\mathrm{n} / \mathrm{a}$ & M & $\mathrm{S}$ & W & Moderate \\
\hline Peng et al. [108] & $\mathrm{W}$ & M & $\mathrm{n} / \mathrm{a}$ & M & $\mathrm{S}$ & $\mathrm{S}$ & Moderate \\
\hline Raak et al. [109] & W & M & $\mathrm{n} / \mathrm{a}$ & M & $\mathrm{S}$ & $\mathrm{S}$ & Moderate \\
\hline Rantonen et al. [110] & M & $\mathrm{S}$ & $\mathrm{S}$ & M & $\mathrm{S}$ & $\mathrm{S}$ & Strong \\
\hline Rasmussen-Barr et al. [111] & M & $\mathrm{S}$ & $\mathrm{S}$ & M & $\mathrm{S}$ & M & Strong \\
\hline Rhyne et al. [112] & W & M & $\mathrm{n} / \mathrm{a}$ & M & $\mathrm{S}$ & M & Moderate \\
\hline Udby et al. [113] & M & M & $\mathrm{S}$ & M & $\mathrm{S}$ & $\mathrm{S}$ & Strong \\
\hline Van Hoof et al. [114] & $\mathrm{W}$ & M & $\mathrm{n} / \mathrm{a}$ & M & $\mathrm{S}$ & $\mathrm{S}$ & Moderate \\
\hline Vibe Fersum et al. [115] & $\mathrm{S}$ & $\mathrm{S}$ & $\mathrm{S}$ & $\mathrm{W}$ & $\mathrm{S}$ & W & Weak \\
\hline \multicolumn{8}{|c|}{ Studies comparing invasive and conservative treatments } \\
\hline Brox et al. [116] & M & $\mathrm{S}$ & $\mathrm{S}$ & M & $\mathrm{S}$ & $\mathrm{S}$ & Strong \\
\hline Froholdt et al. et al. [117] & M & $S$ & $\mathrm{~S}$ & M & $S$ & S & Strong \\
\hline Froholdt et al. [118] & $\mathrm{S}$ & $S$ & $\mathrm{~S}$ & M & $S$ & M & Strong \\
\hline Furunes et al. [119] & M & $\mathrm{S}$ & W & M & $\mathrm{S}$ & $\mathrm{S}$ & Moderate \\
\hline Hedlund et al. [120] & M & $\mathrm{S}$ & $\mathrm{S}$ & M & $\mathrm{S}$ & $\mathrm{S}$ & Strong \\
\hline Kleimeyer et al. [121] & W & M & $S$ & M & $S$ & M & Moderate \\
\hline
\end{tabular}

EPHPP Effective Public Health Practice Project Quality Assessment Tool, $S$ strong, $M$ moderate, $W$ weak, $n / a$ not applicable

a'Withdrawals and dropout' rating varies per time of measurement: strong at 3 years follow-up ( $<20 \%$ dropouts), moderate at 4 years $(<40 \%$ dropouts), and weak at 5, 6, and 7 years follow-up ( $>40 \%$ dropouts) 


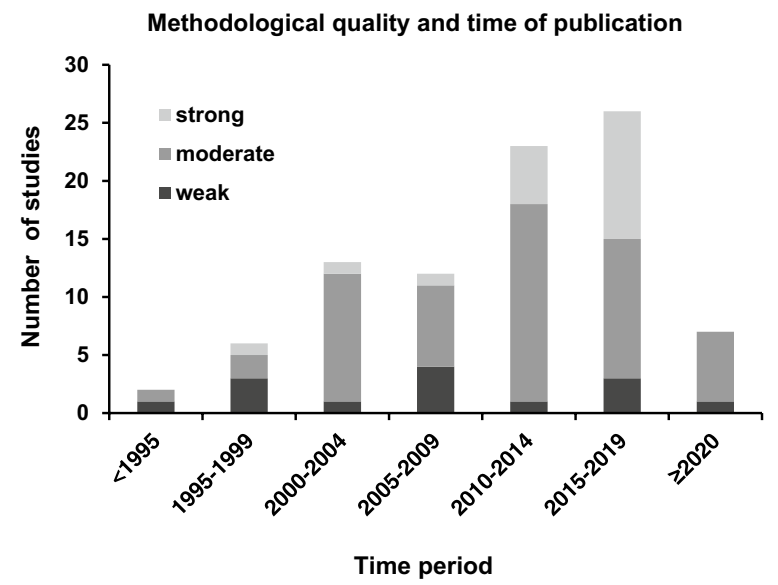

Fig. 2 Number of studies with methodological quality per time period of publication

chiropractic care or primary care by a medical doctor [102], anthroposophic medicine [103], rehabilitation treatment [109], or open label placebo pills [100].

With the exception of two control groups that were assessed in studies on conservative treatments [98, 110], there were no studies examining long-term outcomes of LBP in people receiving no treatment. Two studies reported examining the natural history of LBP; however, their patient samples completed Swedish Back School [106] or received two months of conservative treatment [108] and were therefore categorized under 'conservative treatments' in this review.

\section{Patient characteristics}

Selection criteria of this review were set to include only studies on adults with sub-acute or chronic non-specific LBP. This also included patients with LBP due to FBSS, or degenerative changes such as disk degeneration and grade 1 spondylolisthesis, provided that there were no neurological symptoms. One study exclusively included patients with sub-acute LBP [34] and five studies included both patients with sub-acute and CLBP [102-104, 110, 111].

The majority of studies $(91 \%, n=64)$ on invasive treatments (with or without conservative treatment as a control) included patients that fit their criteria for either degenerative disc disease (DDD), discogenic pain, internal disc disruption or a combination thereof. Other studies selected patients with Modic type 1 or 2 changes [48], patients with CLBP and radiating pain to the lower limb(s) [52], FBSS [55], either FBSS or mechanical LBP [86], or LBP originating from the endplate [77].

Only two studies investigating conservative treatment options sought to include patients with discogenic pain

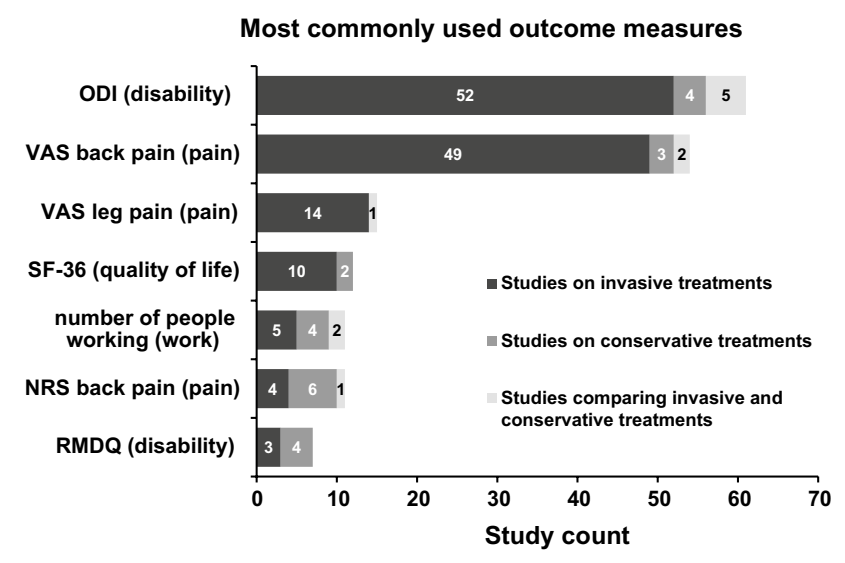

Fig. 3 Most commonly used ( $>5$ studies) patient-centered outcome measures with the corresponding outcome domain in brackets. VAS and NRS without specification of a certain body area (e.g., legs) were classified as VAS back pain and NRS back pain. The Physical Component Scale, General Health Scale and total score of the SF-36 were all classified as SF-36 quality of life measures. ODI, Oswestry Disability Index; VAS, Visual Analogue Scale; SF-36, Short Form (36) Health Survey; NRS, Numerical Rating Scale; RMDQ, Roland Morris Disability Questionnaire

$[108,112]$. One study specifically excluded patients with disk degeneration [100]. Commonly, patients with CLBP $(58 \%, n=11)$, sub-acute LBP [34], or both sub-acute and CLBP $(29 \%, n=5)$ were eligible for inclusion. Added criteria were: still working [111], permanent employment [110], or sick-leave due to LBP [34, 107]. One study reported results separately for patients with CLBP with or without modic changes [113].

\section{Outcomes measurements}

For the selected studies, disability $(92 \%, n=82)$ and pain $(86 \%, n=77)$ were the most commonly measured outcome domains, followed by work $(25 \%, n=22)$, and quality of life $(15 \%, n=13)$ (SDC 2). Only four studies (4\%) measured health care use $[85,99,101,114]$. Five out of seven most frequently used outcome measures were patient reported outcome measures (PROMs) of pain and disability (Fig. 3). The Oswestry Disability Index (ODI) and Visual Analogue Scale (VAS) back pain were used in the majority of studies. Less frequently used outcome measures were the SF-36 subscale 'Bodily Pain' $(6 \%, n=5)$ for measuring pain, the SF-36 subscales 'Physical Functioning' $(4 \%, n=4)$ and 'Role Physical' $(3 \%, n=3)$, the General Functioning Score (3\%, $n=3)$ for disability, and 'work status' $(3 \%, n=3)$ for measuring work participation. A remaining 40 outcome measures, most for measuring pain, were each used by less than three studies. 


\section{Follow-up}

Follow-up ranged between 26 months and 18 years with a median of 51 months (SDC 2). Forty-three studies (48\%) reported an (average) duration of follow-up between 24 and 48 months, 22 (25\%) studies between 49 months and six years, and 24 (27\%) studies over six years. Only ten studies (11\%) took more than one measurement at $>2$ year after baseline. Follow-up was available for $>80 \%$ of patients in 39 studies, between 60 and $80 \%$ in 12 studies, and $<60 \%$ in six studies. The percentage was unclear in six studies. The remaining 26 studies were retrospective studies that included patients based on complete availability of follow-up. Furthermore, a total of 36 studies (all 28 retrospective studies, seven prospective studies, and one RCT [98]) reported only baseline results of those patients that completed a minimum length of follow-up.

\section{Responder analyses}

Twenty-six out of 89 studies (29\%) reported the results of a responder analysis; 23 studies on invasive treatments, two studies on conservative treatments and one study that compared invasive with conservative treatments (SDC 2). An improvement in disability, measured with the ODI, was most commonly used to determine clinical success $(85 \%, n=22)$, followed by an improvement in back pain or leg pain (38\%, $n=10$ ) measured with VAS or NRS. The cut-off for clinical success varied greatly per instrument; 10 different cut-offs were used for the ODI and seven for the VAS or NRS. One study reported clinical success on pain and disability using an improvement in subscales for pain and functioning of the SF-36 [89]. Other studies analyzed improvement in quality of life (SF-36 Physical Component Scale) [67] or improvement in both pain and disability $[44,48,60]$.

\section{Summary of findings at long-term follow-up}

Table 2 summarizes the overall findings of the selected studies per treatment type and duration of follow-up. Reported results were not specified for diagnoses or disease characteristics. Per outcome, the number of treatment arms that showed a significant improvement ('+'), no significant change (' 0 '), or a significant decline compared to baseline ('-') was reported. Several studies did not report p-values for the change in outcome at follow-up ('?'). Results on work related outcomes were very rarely reported with a statistical level of significance. However, almost all results without a reported p-value showed some level of improvement between baseline and long-term follow-up. In general, pain, disability, and quality of life were significantly improved after an invasive intervention. Results after conservative treatments varied between significantly improved or unchanged. One study reported that patients had significantly worsened compared to baseline six years after following a rehabilitation program [109]. Since most studies reported significant improvement at follow-up, there was little difference in outcome at the different durations of follow-up.

\section{Responder analyses}

Setting aside the variety in definitions to determine clinical success and irrespective of the type of treatment patients received, we found that response on pain measures at longterm follow-up varied between 20 and $90 \%$ (10 studies with 15 treatment arms) and response on disability measures varied between 15 and $91 \%$ (22 studies with 32 treatment arms) (SDC 2).

Looking at different treatment types and taking into account the number of patients per treatment arm, clinical success on disability was achieved in $73 \%$ of patients that underwent a disc arthroplasty ( $n=14$ treatment arms), 75\% of patients that underwent lumbar fusion ( $n=7$ treatment arms), $61 \%$ of patients that received multidisciplinary treatment or physiotherapy/exercise training $(n=4$ treatment arms), and $63 \%$ of patients that received intradiscal therapies ( $n=3$ treatment arms). The only treatment type with $>3$ treatments arms reporting response rates on pain measures was intradiscal therapy ( $n=5$ treatment arms), with $57 \%$ of patients achieving clinical success.

\section{Discussion}

The general purpose of this study was to identify and map the available evidence from long-term studies on chronic non-specific LBP. Our findings confirm the notion that there is little to no information available from natural cohorts when it comes to reporting on patient-centered outcomes other than pain. The majority ( $>75 \%$ ) of papers that were included examined long-term outcomes after invasive treatments. Surgical interventions, specifically lumbar fusion and disc arthroplasty, were most commonly reported. Among studies examining conservative treatments, physical therapy and multidisciplinary programs were most common. Overall, included studies were predominantly of moderate quality and differed in design, patient samples, and methods of data collection. These differences were most profound between studies on invasive and conservative treatments. In general, most studies reported improvements in pain and disability and, when measured, quality of life at long-term follow-up.

This review identifies several knowledge gaps regarding research into long-term outcomes of non-specific chronic LBP. First, there is still little insight into the natural course of LBP regarding outcomes such as disability, quality of 


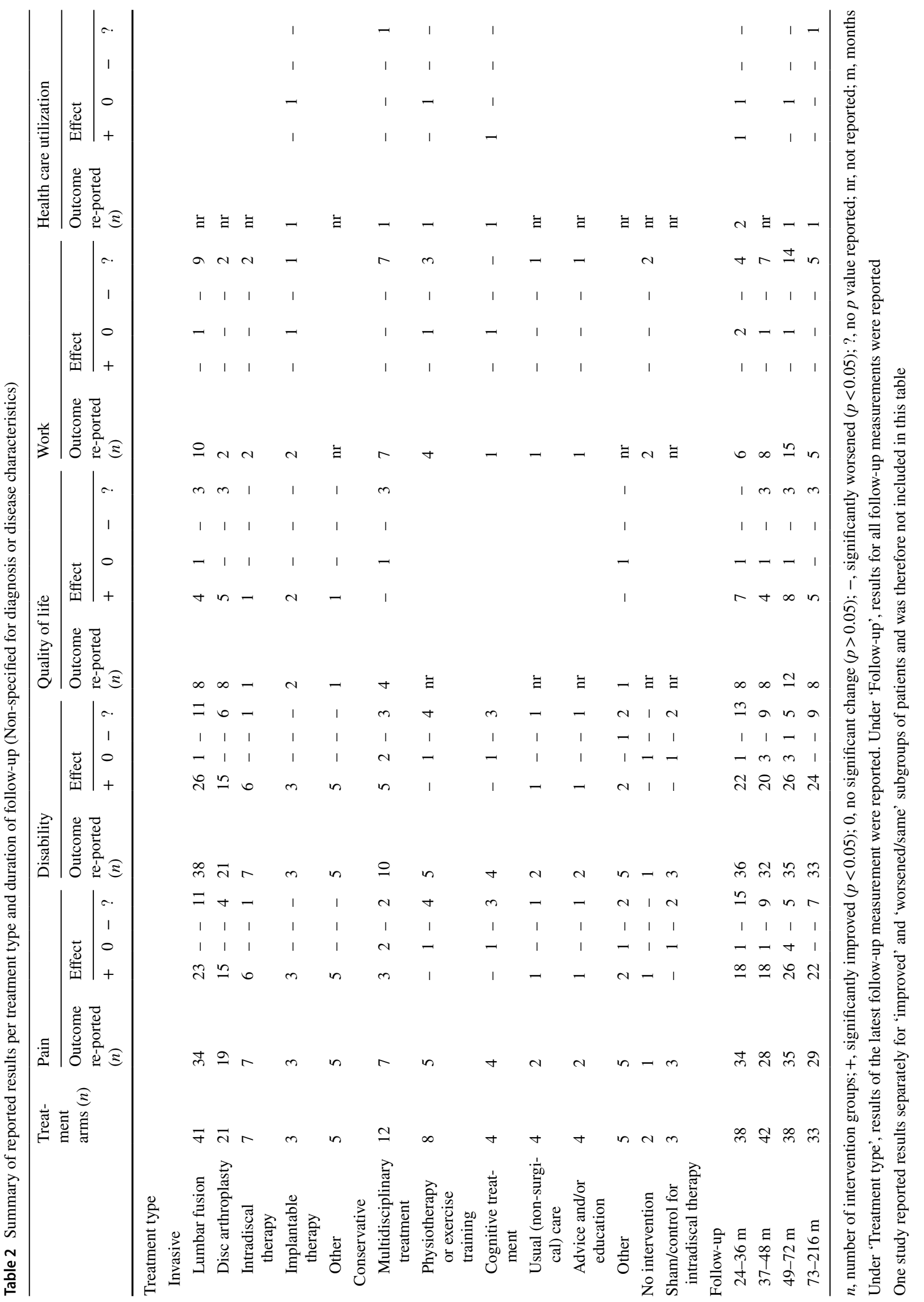


life, work, and health care utilization, because no natural cohorts met the inclusion criteria. In a natural cohort, subjects would be followed in real life in which numerous situations and interventions may appear. It is not limited to one or several specified interventions to study its effect. The studies included in this review examined clinical outcomes of non-specific LBP and concerned patients that were actively seeking health-care. Therefore, they might not be representative of people with sub-chronic or chronic LBP in the general population. Secondly, we noticed that repeated measurements during long-term follow-up were scarce. Only ten studies (11\%) took more than one measurement after the two-year mark. These studies reported lasting improvements in symptoms after lumbar fusion [31, 32, 40, 41, 59, 72], disc arthroplasty [53, 58, 76, 92], and chiropractic care or primary care by an MD [102]. Nonetheless, recurrence of LBP is very common and studies with less than two years follow-up have also shown that post-treatment trajectories of pain and disability can vary a great deal between patients [122-124]. Third, the present review also affirms the notion that across LBP trials, the primary focus has been on pain and disability as outcome measures [125], even though other (generic) measures of health and well-being, such as quality of life and work (dis)ability have been recommended in core outcome sets to reflect the multidimensionality of LBP $[15,126-128]$. Furthermore, few studies seem to monitor health care utilization during follow-up. These data can be challenging to collect; however, they are an important piece of the puzzle in determining whether outcomes at long-term follow-up might be the result of the original intervention (at baseline) or other interventions that were provide during follow-up. To conclude, in order to really understand both the (natural) course of LBP and results of LBP-related interventions over time, frequent measurements of relevant patient-centered outcomes are needed, as well as the use of complete core outcome sets including quality of life and work disability, and an overview of patients' health care utilization during follow-up.

Even though the patient reported outcome measures in this review seem to reflect more positive long-term pain, disability and quality of life status compared to baseline measurements, this should not be misinterpreted as treatment effectiveness. This scoping review was not designed to study long-term effectiveness of interventions. A number of factors might have contributed to the appearance of consistent improvement years after experiencing persistent LBP. First, the reported improvements derive from statistical significance and do not necessarily imply clinical relevance. It is unclear whether patients perceived their improvement on different outcome measures as clinically relevant. Only a select number of studies performed a responder analysis. A previous review on outcome measures also reported that merely $8 \%$ of 401 included LBP trials reported a number or proportion of improved patients [125]. Although most of the studies in the present review that included a responder analysis reported high percentages of patients with clinically relevant improvement, cut-off scores for clinical success varied greatly. For instance, in some studies relative improvements of $25-30 \%$ on VAS or ODI were deemed successful, while others aimed for 50\% [35-37, 95].

Other factors might also have influenced improvement in LBP symptoms. A previous review in patients with nonspecific LBP found that response to primary care treatment followed a pattern of rapid early improvement followed by a plateau, regardless of whether active treatment, usual care, or placebo treatment was used [129]. Natural prognosis could be one explanation $[10,11,130]$. However, natural prognosis at long-term is mostly unknown. People are also more likely to seek health care at a time when their pain and symptoms are at their worst or most debilitating, which could further explain a positive overall course. Regression to the mean could also have played a role in the improvements in symptoms that were found after the start of treatment [131]. Overall, these factors likely influenced short-term improvements in LBP complaints, but if maintained, could also explain the reported long-term beneficial outcomes. Finally, publication and reporting bias cannot be ruled out. Only one study reported that patients had significantly worsened at long-term follow-up. Future (systematic) reviews on long-term studies on LBP should consider checking their findings against reported study protocols and/or unpublished trial data.

Surgical treatments are relatively over-represented in the present review. Safety issues and long-term adverse events are of more concern in surgical trials compared to conservative interventions, which may be why long-term data is collected and analyzed more often from invasive interventions. Also, surgical studies more often seem to utilize data that are retrospectively obtained from patient medical records [132, 133]. This makes it easier to collect and report long-term follow-up data. In spine surgery, complication incidence is potentially underestimated with retrospective assessments [134]; however, the present review includes results from PROMs and not occurrence of adverse events.

Studies on invasive and conservative treatments were notably different in their patient inclusion criteria. Invasive studies sought to include patients with disc-related diagnoses or symptoms, whereas conservative studies defined symptom-related criteria more generally ('low back pain'). Although diagnoses based on lumbar structures (e.g., discogenic pain, facet joint pain) were very common in some settings, diagnostic tests do not reliably identify these structures as a source of LBP. The usefulness of these tests in clinical practice remains unclear [22, $26,135]$ and current guidelines on LBP usually classify these diagnoses as non-specific [136]. Nevertheless, spine 
surgeons have claimed that these diagnoses should classify as specific LBP and that better and earlier identification combined with, if indicated, invasive treatment would improve prognosis in these patients [137]. A Dutch task force that was tasked to develop a guideline for invasive treatment of lumbosacral pain syndromes has proposed to classify diagnoses such as facet joint pain, disc pain and FBSS as 'degenerative uncomplicated spinal LBP syndromes' [138]. In short, LBP diagnoses, as well as the decision to operate or treat conservatively, vary between countries and between medical disciplines. At present, there is no consensus among health care professionals on the classification of specific versus non-specific LBP. Improved consensus on a classification system could lead to more targeted care, reduce the need for expensive diagnostic methods, and facilitate comparison among LBP studies $[17,139,140]$

In line with worldwide research in the field of back pain, we identified a significant increase in annual publications on long-term outcomes of non-specific LBP [141]. The majority of selected studies were from Western countries, with the USA being the most productive ( $26 \%$ of studies). Little to no research took place in lowor middle-income countries, while in the past few decades the largest increases in disability due to LBP have occurred there $[9,142]$. The impact of LBP in low- to middle-income countries potentially comes with disadvantages dissimilar to those in high-income countries and might therefore not be represented in the present review [9].

Finally, methodological quality of studies seemed to also increase over the years. Only prospectively conducted studies (prospective cohorts and RCT/CCTs) received a global 'strong' rating with the quality assessment tool that was utilized. Selection bias was often present in retrospectively conducted studies. In these instances, patients were included based on complete availability of follow-up data. Two sensitivity analyses were performed on the scoring method of the quality assessment tool. First, the global quality rating of a study was determined by the amount of 'weak' ratings that was scored on all separate domains. This means that studies that scored 'moderate' on each separate domain would have received a 'strong' global rating. A separate analysis showed that changing the global rating from strong to moderate for these studies would have had no effect on the results, since there were no studies that rated moderate on each domain. Second, prospective cohort studies received a 'moderate' rating on the domain study design. It could be argued that prospective cohort studies are a strong design for studying long-term outcomes. However, changing these ratings from moderate to strong on this domain would have also had no effect on the global quality rating.

\section{Limitations}

As to be expected, a number of studies on long-term LBP outcomes had to be excluded from this review after not meeting our inclusion criteria. This occurred most often with studies on samples with non-specific LBP mixed with specific LBP, samples with acute mixed with sub-acute and chronic LBP, and studies that failed to report baseline results of the outcomes measured at long-term follow-up. The latter in particular was common for measures related to health care utilization, since information has to be available, or recalled, from before baseline. Ultimately, only four studies could be included that reported health care use in the period before baseline [85, 99, 101, 114]. Another limitation is that this review gives limited insight into when the improvements that we observed took place. We chose to only report results from long-term follow-up ( $>2$ years), since the focus of was on mapping evidence from long-term follow-up studies. The complete course or trajectory of LBP symptoms could be studied in future reviews with a more narrow scope. Finally, the heterogeneity in the assessment and reporting of outcomes rendered it difficult to provide a qualitative synthesis of the results. A wide variety of instruments was used to measure pain, disability, quality of life, and work participation, and a considerable amount of studies did not report whether changes in scores between baseline and follow-up were statistically significant.

\section{Conclusion}

Patients with persistent non-specific LBP report improvements in pain, disability and quality of life years after seeking treatment. However, it remains unclear what factors might have influenced these improvements, and whether they are treatment-related. In part, because there is very little long-term evidence available from natural cohorts. Finally, studies that examined long-term outcomes of LBP symptoms varied greatly in design, quality, patient samples, and methods of data collection, and only few performed a responder analysis or applied repeated measurements after two years of follow-up.

Supplementary Information The online version contains supplementary material available at https://doi.org/10.1007/s00586-022-07111-3.

Author contributions All authors contributed to the study conception and design. The literature search was performed by AL Dutmer and data analysis was performed by AL Dutmer, R Soer, MF Reneman, and HR Schiphorst Preuper. The first draft of the manuscript was written by AL Dutmer and all authors commented on previous versions of the manuscript. All authors read and approved the final manuscript. 
Funding No funding was received for conducting this study.

Data availability All data generated or analysed during this study are included in this published article and its supplementary information files.

Code availability Not applicable.

\section{Declarations}

Conflict of interest The authors have no relevant financial or non-financial interests to disclose.

Open Access This article is licensed under a Creative Commons Attribution 4.0 International License, which permits use, sharing, adaptation, distribution and reproduction in any medium or format, as long as you give appropriate credit to the original author(s) and the source, provide a link to the Creative Commons licence, and indicate if changes were made. The images or other third party material in this article are included in the article's Creative Commons licence, unless indicated otherwise in a credit line to the material. If material is not included in the article's Creative Commons licence and your intended use is not permitted by statutory regulation or exceeds the permitted use, you will need to obtain permission directly from the copyright holder. To view a copy of this licence, visit http://creativecommons.org/licenses/by/4.0/.

\section{References}

1. GBD 2017 Disease and Injury Incidence and Prevalence Collaborators (2008) (2018) Global, regional, and national incidence, prevalence, and years lived with disability for 354 diseases and injuries for 195 countries and territories, 1990-2017: a systematic analysis for the Global Burden of Disease Study. Lancet 392(10159):1789-1858. https://doi.org/10.1016/s0140-6736(18) 32279-7

2. Walker BF (2000) The prevalence of low back pain: a systematic review of the literature from 1966 to 1998. J Spinal Disord 13(3):205-217. https://doi.org/10.1097/00002517-20000 6000-00003

3. Koes BW, van Tulder MW, Thomas S (2006) Diagnosis and treatment of low back pain. BMJ 332(7555):1430-1434. https://doi. org/10.1136/bmj.332.7555.1430

4. Cassidy JD, Carroll LJ, Côté P (1998) The Saskatchewan health and back pain survey. The prevalence of low back pain and related disability in Saskatchewan adults. Spine (Phila Pa 1976) 23(17):1860-6. https://doi.org/10.1097/00007632-19980 9010-00012

5. Picavet HSJ \& Schouten JSAG (2003) Musculoskeletal pain in the Netherlands: prevalences, consequences and risk groups, the DMC(3)-study. Pain 102(1-2):167-178. https://doi.org/10.1016/ s0304-3959(02)00372-x

6. Dutmer AL, Schiphorst Preuper HR, Soer R et al (2019) Personal and societal impact of low back pain: The Groningen Spine Cohort. Spine (Phila Pa 1976) 44:E1443-51. https://doi.org/10. 1097/brs.0000000000003174

7. Montazeri A, Mousavi SJ (2010) Quality of life and low back pain. In: Preedy VR, Watson RR (eds) Handbook of disease burdens and quality of life measures. Springer, New York, pp 3979-3994

8. Lambeek LC, van Tulder MW, Swinkels IC et al (2011) The trend in total cost of back pain in the Netherlands in the period 2002 to
2007. Spine (Phila Pa 1976) 36:1050-8. https://doi.org/10.1097/ brs.0b013e3181e70488

9. Hartvigsen J, Hancock MJ, Kongsted A et al (2018) What low back pain is and why we need to pay attention. Lancet 391:23562367. https://doi.org/10.1016/s0140-6736(18)30480-x

10. Menezes DC, Costa L, Maher CG, Hancock MJ et al (2012) The prognosis of acute and persistent low-back pain: a metaanalysis. CMAJ 184(11):E613-E624. https://doi.org/10.1503/ cmaj.111271

11. Hestbaek L, Leboeuf-Yde C, Manniche C (2003) Low back pain: what is the long-term course? A review of studies of general patient populations. Eur Spine J 12(2):149-165. https://doi.org/ 10.1007/s00586-002-0508-5

12. Itz CJ, Geurts JW, van Kleef M et al (2013) Clinical course of non-specific low back pain: a systematic review of prospective cohort studies set in primary care. Eur J Pain 17(1):5-15. https:// doi.org/10.1002/j.1532-2149.2012.00170.x

13. Dunn KM, Hestbaek L, Cassidy JD (2013) Low back pain across the life course. Best Pract Res Clin Rheumatol 27(5):591-600. https://doi.org/10.1002/j.1532-2149.2012.00170.x

14. Lemeunier N, Leboeuf-Yde C, Gagey O (2012) The natural course of low back pain: a systematic critical literature review. Chiropr Man Ther 20(1):33. https://doi.org/10.1186/ 2045-709x-20-33

15. Bombardier C (2000) Outcome assessments in the evaluation of treatment of spinal disorders: summary and general recommendations. Spine (Phila Pa 1976) 25(24):3100-3. https://doi. org/10.1097/00007632-200012150-00003

16. Dworkin RH, Turk DC, Farrar JT et al (2005) Core outcome measures for chronic pain clinical trials: IMMPACT recommendations. Pain 113(1-2):9-19. https://doi.org/10.1016/j.pain.2004. 09.012

17. Deyo RA, Dworkin SF, Amtmann D et al (2014) Report of the NIH task force on research standards for chronic low back pain. Spine (Phila Pa 1976) 39:1128-43. https://doi.org/10.1097/brs. 0000000000002421

18. Arksey H, O'Malley L (2005) Scoping studies: towards a methodological framework. Int J Soc Res Methodol 8(1):19-32. https://doi.org/10.1080/1364557032000119616

19. Munn Z, Peters MDJ, Stern C et al (2018) Systematic review or scoping review? Guidance for authors when choosing between a systematic or scoping review approach. BMC Med Res Methodol 18(1):143. https://doi.org/10.1186/s12874-018-0611-x

20. Tricco AC, Lillie E, Zarin W et al (2018) PRISMA extension for scoping reviews (PRISMA-ScR): checklist and explanation. Ann Intern Med 169(7):467-473. https://doi.org/10.7326/m18-0850

21. Pham MT, Rajić A, Greid JD et al (2014) A scoping review of scoping reviews: advancing the approach and enhancing the consistency. Res Synth Methods 5(4):371-385. https://doi.org/ 10.1002/jrsm. 1123

22. Hancock MJ, Maher CG, Latimer J et al (2007) Systematic review of tests to identify the disc, SIJ or facet joint as the source of low back pain. Eur Spine J 16(10):1539-50. https://doi.org/10. 1007/s00586-007-0391-1

23. Jacobsen S, Sonne-Halm S, Rovsing H et al (2007) Degenerative lumbar spondylolisthesis: an epidemiological perspective: the Copenhagen Osteoarthritis Study. Spine (Phila Pa 1976) 32(1):120-5. https://doi.org/10.1097/01.brs.0000250979.12398. 96

24. Kalichman L, Li L, Kim DH et al (2008) Facet joint osteoarthritis and low back pain in the community-based population. Spine (Phila Pa 1976) 33(23):2560-5. https://doi.org/10.1097/ brs.0b013e318184ef95

25. Brinjikji W, Diehn FE, Jarvik JG et al (2015) MRI Findings of disc degeneration are more prevalent in adults with low back pain than in asymptomatic controls: a systematic review and 
meta-analysis. AJNR Am J Neuroradiol 36(12):2394-2399. https://doi.org/10.3174/ajnr.a4498

26. Maas ET, Juch JNS, Ostelo RWJG et al (2017) Systematic review of patient history and physical examination to diagnose chronic low back pain originating from the facet joints. Eur $\mathbf{J}$ Pain 21(3):403-414. https://doi.org/10.1002/ejp.963

27. Viera AJ, Garrett Joanne M (2005) Understanding interobserver agreement: the kappa statistic. Fam Med 37(5):360-363

28. Thomas BH, Ciliska D, Dobbins M et al (2004) A process for systematically reviewing the literature: providing the research evidence for public health nursing interventions. Worldviews Evid Based Nurs 1(3):176-184. https://doi.org/10.1111/j.1524475x.2004.04006.x

29. Armijo-Olivo S, Stiles CR, Hagen NA et al (2012) Assessment of study quality for systematic reviews: a comparison of the Cochrane Collaboration Risk of Bias Tool and the Effective Public Health Practice Project Quality Assessment Tool: methodological research. J Eval Clin Pract 18(1):12-18. https://doi. org/10.1111/j.1365-2753.2010.01516.x

30. Henschke N, van Enst A, Froud R et al (2014) Responder analyses in randomised controlled trials for chronic low back pain: an overview of currently used methods. Eur Spine J 23(4):772-778. https://doi.org/10.1007/s00586-013-3155-0

31. Butterman GR, Thorson TM, Mullin WJ (2014) Outcomes of posterior facet versus pedicle screw fixation of circumferential fusion: a cohort study. Eur Spine J 23(2):347-355. https://doi. org/10.1007/s00586-013-2999-7

32. Butterman GR, Hollmann S, Arpino J et al (2020) Value of single-level circumferential fusion: a 10 -year prospective outcomes and cost-effectiveness analysis comparing posterior facet versus pedicle screw fixation. Eur Spine J 29(2):360-373. https://doi. org/10.1007/s00586-019-06165-0

33. Cousins S, Blencowe NS, Blazeby JM (2019) What is an invasive procedure? A definition to inform study design, evidence synthesis and research tracking. BMJ Open 9(7):E028576. https://doi. org/10.1136/bmjopen-2018-028576

34. Indahl A, Haldorsen EH, Holm S et al (1998) Five-year followup study of a controlled clinical trial using light mobilization and an informative approach to low back pain. Spine (Phila Pa 1976) 23(23):2625-30. https://doi.org/10.1097/00007632-19981 2010-00018

35. Al-Kaisy A, Palmisani S, Smith TE et al (2018) Long-Term improvements in chronic axial low back pain patients without previous spinal surgery: a cohort analysis of $10-\mathrm{kHz}$ highfrequency spinal cord stimulation over 36 months. Pain Med 19(6):1219-1226. https://doi.org/10.1093/pm/pnx237

36. Amirdelfan K, Bae H, McJunkin T et al (2021) Allogeneic mesenchymal precursor cells treatment for chronic low back pain associated with degenerative disc disease: a prospective randomized, placebo-controlled 36-month study of safety and efficacy. Spine J 21(2):212-230. https://doi.org/10.1016/j.spinee. 2020.10.004

37. Aunoble S, Meyrat R, Al Sawad Y et al (2010) Hybrid construct for two levels disc disease in lumbar spine. Eur Spine J 19(2):290-296. https://doi.org/10.1007/s00586-009-1182-7

38. Axelsson P, Johnsson R, Strömqvist B et al (1994) Posterolateral lumbar fusion. Outcome of 71 consecutive operations after 4 (2-7) years. Act Orthop Scand 65(3):309-14. https://doi.org/10. 3109/17453679408995459

39. Buric J, Pulidori M (2011) Long-term reduction in pain and disability after surgery with the interspinous device for intervertebral assisted motion (DIAM) spinal stabilization system in patients with low back pain: 4-year follow-up from a longitudinal prospective case series. Eur Spine J 20(8):1204-1211. https://doi. org/10.1007/s00586-011-1697-6
40. Burkus JK, Gornet MF, Schuler TC et al (2009) Six-year outcomes of anterior lumbar interbody arthrodesis with use of interbody fusion cages and recombinant human bone morphogenetic protein-2. J Bone Joint Surg Am 91(5):1181-1189. https://doi. org/10.2106/jbjs.g.01485

41. Butterman GR, Mullin WJ (2015) Two-level circumferential lumbar fusion comparing midline and paraspinal posterior approach: 5 -year interim outcomes of a randomized, blinded, prospective study. J Spinal Disord Tech 28(9):E534-E543. https://doi.org/ 10.1097/bsd.0000000000000029

42. Cakir B, Schmidt R, Mattes T et al (2009) Index level mobility after total lumbar disc replacement: is it beneficial or detrimental? Spine (Phila Pa 1976) 34(9):917-23. https://doi.org/10.1097/ brs.0b013e31819b213c

43. Cheng J, Zheng W, Wang H et al (2014) Posterolateral transforaminal selective endoscopic diskectomy with thermal annuloplasty for discogenic low back pain: a prospective observational study. Spine (Phila Pa 1976) 39(26 Spec No):B60-B65. https:// doi.org/10.1097/brs.0000000000000495

44. Cheng J, Santiago KA, Nguyen JT et al (2019) Treatment of symptomatic degenerative intervertebral discs with autologous platelet-rich plasma: follow-up at 5-9 years. Regen Med 14(9):831-840. https://doi.org/10.2217/rme-2019-0040

45. Chung SK, Lee SH, Lim SR et al (2003) Comparative study of laparoscopic L5-S1 fusion versus open mini-ALIF, with a minimum 2-year follow-up. Eur Spine J 12(6):613-617. https://doi. org/10.1007/s00586-003-0526-y

46. Corenman DS, Gillard DM, Dornan GJ et al (2013) Recombinant human bone morphogenetic protein-2-augmented transforaminal lumbar interbody fusion for the treatment of chronic low back pain secondary to the homogeneous diagnosis of discogenic pain syndrome: two-year outcomes. Spine (Phila Pa 1976) 38(20):E1269-77. https://doi.org/10.1097/brs.0b013e31829fc56f

47. Di Silvestre M, Bakaloudis G, Lolli F et al (2009) Two-level total lumbar disc replacement. Eur Spine J 18(Suppl 1):64-70. https:// doi.org/10.1007/s00586-009-0982-0

48. Fischgrund JS, Rhyne A, Macadaeg K et al (2020) Long-term outcomes following intraosseous basivertebral nerve ablation for the treatment of chronic low back pain: 5-year treatment arm results from a prospective randomized double-blind sham-controlled multi-center study. Eur Spine J 29(8):1925-1934. https:// doi.org/10.1007/s00586-020-06448-x

49. Formica C, Zanarito A, Divano S et al (2020) Total disc replacement for lumbar degenerative disc disease: single centre 20 years experience. Eur Spine J 29(7):1518-1526. https://doi.org/10. 1007/s00586-019-06100-3

50. Geerdes BP, Geukers CW, van Erp WF (2001) Laparoscopic spinal fusion of L4-L5 and L5-S1. Surg Endosc 15(11):1308-1312. https://doi.org/10.1007/s004640000184

51. Gepstein R, Werner D, Shabat S et al (2005) Percutaneous posterior lumbar interbody fusion using the B-twin expandable spinal spacer. Minim Invasive Neurosurg 48(6):330-333

52. Gioia G, Mandelli D, Randelli F (2007) The Charité III Artificial Disc lumbar disc prosthesis: assessment of medium-term results. J Orthop Traumatol 8(3):134-139. https://doi.org/10.1097/00007 632-199604150-00015

53. Gornet MF, Burkus JK, Dryer RF et al (2019) Lumbar disc arthroplasty versus anterior lumbar interbody fusion: 5-year outcomes for patients in the Maverick disc investigational device exemption study. Neurosurg Spine 31(3):347-356. https://doi. org/10.3171/2019.2.spine181037

54. Guyer RD, McAfee PC, Banco RJ et al (2009) Prospective, randomized, multicenter Food and Drug Administration investigational device exemption study of lumbar total disc replacement with the CHARITE artificial disc versus lumbar fusion: 
five-year follow-up. Spine J 9(5):374-386. https://doi.org/10. 1016/j.spinee.2008.08.007

55. Hamm-Faber TE, Aukes H, van Gorp E et al (2015) Subcutaneous stimulation as an additional therapy to spinal cord stimulation for the treatment of low back pain and leg pain in failed back surgery syndrome: four-year follow-up. Neuromodulation 18(7):618-622. https://doi.org/10.1111/ner.12309

56. Houten JK, Post NH, Dryer JW et al (2006) Clinical and radiographically/neuroimaging documented outcome in transforaminal lumbar interbody fusion. Neurosurg Focus 20(3):E8. https:// doi.org/10.3171/foc.2006.20.3.9

57. Kareem H, Ulbricht $\mathrm{C}$ (2020) A Prospective long-term follow-up study of the posterior dynamic stabilizing system to treat back pain associated with degenerative disc disease. Glob Spine $\mathbf{J}$ 10(1):30-38. https://doi.org/10.1177/2192568219844236

58. Katsimihas M, Baily CS, Issa K et al (2010) Prospective clinical and radiographic results of CHARITÉ III artificial total disc arthroplasty at 2- to 7-year follow-up: a Canadian experience. Can J Surg 53(6):408-414

59. Kuslich SD, Danielson G, Dowdle JD et al (2000) Four-year follow-up results of lumbar spine arthrodesis using the Bagby and Kuslich lumbar fusion cage. Spine (Phila pa 1976) 25(20):265662. https://doi.org/10.1097/00007632-200010150-00018

60. Lee MS, Cooper G, Lutz GE et al (2003) Intradiscal electrothermal therapy (IDET) for treatment of chronic lumbar discogenic pain: a minimum 2-year clinical outcome study. Pain Phys 6(4):443-448

61. Liang Y, Shi W, Jiang C et al (2015) Clinical outcomes and sagittal alignment of single-level unilateral instrumented transforaminal lumbar interbody fusion with a 4 to 5 -year followup. Eur Spine J 24(11):2560-2566. https://doi.org/10.1007/ s00586-015-3933-y

62. Lu S, Hai Y, Kong C et al (2015) An 11-year minimum follow-up of the Charite III lumbar disc replacement for the treatment of symptomatic degenerative disc disease. Eur Spine J 24(9):20562064. https://doi.org/10.1007/s00586-015-3939-5

63. Lu K, Liliang P, Wang $\mathrm{H}$ et al (2016) Clinical outcome following DIAM implantation for symptomatic lumbar internal disk disruption: a 3-year retrospective analysis. J Pain Res 9:917-924. https://doi.org/10.2147/jpr.s115847

64. Madan S, Boeree NR (2001) Containment and stabilization of bone graft in anterior lumbar interbody fusion: the role of the Hartshill Horseshoe cage. J Spinal Disord 14(2):104-108. https:// doi.org/10.1097/00002517-200104000-00003

65. Madan SS, Harley JM, Boeree NN (2003) Circumferential and posterolateral fusion for lumbar disc disease. Clin Orthop Relat Res 409:114-123. https://doi.org/10.1097/01.blo.0000059581. 08469.77

66. Maestretti G, Reischl N, Jacobi M et al (2011) Treatment of discogenic low back pain by total disc arthroplasty using the Prodisc prosthesis: analysis of a prospective cohort study with five-year clinical follow-up. Open Spine J 3:16-20. https://doi. org/10.2174/1876532701103010016

67. Malham GM, Parker RM (2017) Early experience with lateral lumbar total disc replacement: utility, complications and revision strategies. J Clin Neurosci 39:176-183. https://doi.org/10.1016/j. jocn.2017.01.033

68. Meir AR, Freeman BJC, Fraser RD et al (2013) Ten-year survival and clinical outcome of the AcroFlex lumbar disc replacement for the treatment of symptomatic disc degeneration. Spine J 13(1):13-21. https://doi.org/10.1016/j.spinee.2012.12.008

69. Niemeyer T, Bövingloh AS, Halm H et al (2004) Results after anterior-posterior lumbar spinal fusion: $2-5$ years follow-up. Int Orthop 28(5):298-302. https://doi.org/10.1007/ s00264-004-0577-7
70. Noriega DC, Ardura F, Hernández-Ramajo R et al (2021) Treatment of degenerative disc disease with allogeneic mesenchymal stem cells: long-term follow-up results. Transplantation 105(2):E25-E27. https://doi.org/10.1097/tp.0000000000003471

71. Nunley PD, Jawahar A, Brandao SM et al (2008) Intradiscal electrothermal therapy (IDET) for low back pain in worker's compensation patients: can it provide a potential answer? Longterm results. J Spinal Disord Tech 21(1):11-18. https://doi.org/ 10.1097/bsd.0b013e31804c990e

72. Nystrom B, Weber H, Schillberg B et al (2018) Symptoms and signs possibly indicating segmental, discogenic pain. A fusion study with 18 years of follow-up. Scand J Pain 16:213-220. https://doi.org/10.1016/j.sjpain.2016.10.007

73. Ohtori S, Kinoshita T, Yamashita M et al (2009) Results of surgery for discogenic low back pain: a randomized study using discography versus discoblock for diagnosis. Spine (Phila Pa 1976) 34(13):1345-8. https://doi.org/10.1097/brs.0b013e3181 a401bf

74. Pan F, Shen B, Chy SK et al (2016) Transforaminal endoscopic system technique for discogenic low back pain: a prospective Cohort study. Int J Surg 35:134-138. https://doi.org/10.1016/j. ijsu.2016.09.091

75. Park C, Ryu K, Lee K et al (2012) Clinical outcome of lumbar total disc replacement using ProDisc-L in degenerative disc disease: minimum 5-year follow-up results at a single institute. Spine (Phila Pa 1976) 37(8):672-7. https://doi.org/10.1097/brs. 0b013e31822ecd85

76. Park S, Lee C, Chung S et al (2016) Long-term outcomes following lumbar total disc replacement using ProDisc-II: average 10-year follow-up at a single institute. Spine (Phila Pa 1976) 41(11):971-7. https://doi.org/10.1097/brs.0000000000001527

77. Peng B, Chen J, Kuang Z et al (2009) Diagnosis and surgical treatment of back pain originating from endplate. Eur Spine $\mathrm{J}$ 18(7):1035-1040. https://doi.org/10.1007/s00586-009-0938-4

78. Petilon J, Roth J, Hardenbrook M (2011) Results of lumbar total disc arthroplasty in military personnel. J Spinal Disord Tech 24(5):297-301. https://doi.org/10.1097/bsd.0b013e3181fb3e2a

79. Pettine K, Suzuki R, Sand T et al (2017) Autologous bone marrow concentrate intradiscal injection for the treatment of degenerative disc disease with three-year follow-up. Int Orthop 41(10):2097-2103. https://doi.org/10.1007/s00264-017-3560-9

80. Pihlajamäki H, Böstman O, Ruuskanen M et al (1996) Posterolateral lumbosacral fusion with transpedicular fixation: 63 consecutive cases followed for 4 (2-6) years. Acta Orthop Scand 67(1):63-68. https://doi.org/10.3109/17453679608995612

81. Pimenta L, Marchi L, Oliveira L et al (2013) A prospective, randomized, controlled trial comparing radiographic and clinical outcomes between stand-alone lateral interbody lumbar fusion with either silicate calcium phosphate or rh-BMP2. J Neurol Surg A Cent Eur Neurosurg 74(6):343-350. https://doi.org/10.1055/s0032-1333420

82. Pimenta L, Marchi L, Oliveira L et al (2018) Elastomeric lumbar total disc replacement: clinical and radiological results with minimum 84 months follow-up. Int J Spine Surg 12(1):49-57. https://doi.org/10.14444/5009

83. Plais N, Thevenot X, Cogniet A et al (2018) Maverick total disc arthroplasty performs well at 10 years follow-up: a prospective study with HRQL and balance analysis. Eur Spine J 27(3):720727. https://doi.org/10.1007/s00586-017-5065-z

84. Pokorny G, Marchi L, Amaral R et al (2019) Lumbar total disc replacement by the lateral approach-up to 10 years follow-up. World Neurosurg 122:e325-e333. https://doi.org/10.1016/j. wneu.2018.10.033

85. Putzier M, Hoff E, Tohtz S et al (2010) Dynamic stabilization adjacent to single-level fusion: part II. No clinical benefit for asymptomatic, initially degenerated adjacent segments after 6 
years follow-up. Eur Spine J 19(12):2181-9. https://doi.org/10. 1007/s00586-010-1517-4

86. Raphael JH, Southall JL, Gnanadurai TV et al (2002) Long-term experience with implanted intrathecal drug administration systems for failed back syndrome and chronic mechanical low back pain. BMC Musculoskelet Disord 3:17. https://doi.org/10.1186/ 1471-2474-3-17

87. Ren D, Liu X, Du S et al (2015) Percutaneous nucleoplasty using coblation technique for the treatment of chronic nonspecific low back pain: 5-year follow-up results. Chin Med J (Engl) 128(14):1893-1897. https://doi.org/10.4103/0366-6999.160518

88. Rouben D, Casnellie M, Ferguson M (2011) Long-term durability of minimal invasive posterior transforaminal lumbar interbody fusion: a clinical and radiographic follow-up. J Spinal Disord Tech 24(5):288-296. https://doi.org/10.1097/bsd.0b013 e3181f9a60a

89. Saal JA, Saal JS (2002) Intradiscal electrothermal treatment for chronic discogenic low back pain: prospective outcome study with a minimum 2-year follow-up. Spine (Phila $\mathrm{Pa}$ 1976) 27(9):966-73. https://doi.org/10.1097/00007632-20020 5010-00017

90. Schimmel JJP, Poeshmann MS, Horsting PP et al (2016) PEEK cages in lumbar fusion: mid-term clinical outcome and radiologic fusion. Clin Spine Surg 29(5):E252-E258. https://doi. org/10.1097/bsd.0b013e31826eaf74

91. Schulte TL, Leistra F, Bullmann V et al (2007) Disc height reduction in adjacent segments and clinical outcome 10 years after lumbar 360 degrees fusion. Eur Spine J 16(12):21522158. https://doi.org/10.1007/s00586-007-0515-7

92. Siepe CJ, Heider F, Wiechert K et al (2014) Mid- to long-term results of total lumbar disc replacement: a prospective analysis with 5- to 10-year follow-up. Spine J 14(8):1417-1431. https:// doi.org/10.1016/j.spinee.2013.08.028

93. Sköld C, Tropp H, Berg S (2013) Five-year follow-up of total disc replacement compared to fusion: a randomized controlled trial. Eur Spine J 22(10):2288-2295. https://doi.org/10.1007/ s00586-013-2926-y

94. Strube P, Hoff EK, Schürings M et al (2013) Parameters influencing the outcome after total disc replacement at the lumbosacral junction. Part 2: distraction and posterior translation lead to clinical failure after a mean follow-up of 5 years. Eur Spine J 22(10):2279-87. https://doi.org/10.1007/s00586-013-2967-2

95. Thalgott JS, Klezl Z, Timlin M et al (2002) Anterior lumbar interbody fusion with processed sea coral (coralline hydroxyapatite) as part of a circumferential fusion. Spine (Phila Pa 1976) 27(24):E518-E25. https://doi.org/10.1097/ 00007632-200212150-00011

96. Wuertinger C, Annes RDA, Hitzl W et al (2018) Motion preservation following total lumbar disc replacement at the lumbosacral junction: a prospective long-term clinical and radiographic investigation. Spine J 18(1):72-80. https://doi.org/10. 1016/j.spinee.2017.06.035

97. Zeilstra DJ, Staartjes VE, Schröder ML (2017) Minimally invasive transaxial lumbosacral interbody fusion: a ten year single-centre experience. Int Orthop 41(1):113-119

98. Bendix AE, Bendix T, Haestrup C et al (1998) A prospective, randomized 5-year follow-up study of functional restoration in chronic low back pain patients. Eur Spine J 7(2):111-119. https://doi.org/10.1007/s005860050040

99. Bentsen H, Lindgärde F, Manthorpe R (1997) The effect of dynamic strength back exercise and/or a home training program in 57-year-old women with chronic low back pain. Results of a prospective randomized study with a 3 -year follow-up period. Spine (Phila Pa 1976) 22(13):1494-500. https://doi.org/10. 1097/00007632-199707010-00014
100. Carvalho C, Pais M, Cunha L et al (2021) Open-label placebo for chronic low back pain: a 5-year follow-up. Pain 162(5):1521-1527. https://doi.org/10.1097/j.pain.0000000000 002162

101. Groot D, van Hooff ML, Kroeze RJ et al (2019) Long-term results of an intensive cognitive behavioral pain management program for patients with chronic low back pain: a concise report of an extended cohort with a minimum of 5-year follow-up. Eur Spine J 28(7):1579-1585. https://doi.org/10.1007/s00586-019-05967-6

102. Haas M, Goldberg B, Aickin M et al (2004) A practice-based study of patients with acute and chronic low back pain attending primary care and chiropractic physicians: two-week to 48-month follow-up. J Manip Physiol Ther 27(3):160-169. https://doi.org/ 10.1016/j.jmpt.2003.12.020

103. Hamre HJ, Kiene H, Glockmann A et al (2013) Long-term outcomes of anthroposophic treatment for chronic disease: a four-year follow-up analysis of 1510 patients from a prospective observational study in routine outpatient settings. BMC Res Notes 6:269. https://doi.org/10.1186/1756-0500-6-269

104. Lamb SE, Mistry D, Lall R et al (2012) Group cognitive behavioural interventions for low back pain in primary care: extended follow-up of the Back Skills Training Trial (ISRCTN54717854). Pain 153(2):494-501. https://doi.org/10.1016/j.pain.2011.11.016

105. Lanes TC, Gauron EF, Sprat KF et al (1995) Long-term followup of patients with chronic back pain treated in a multidisciplinary rehabilitation program. Spine (Phila Pa 1976) 20(7):801-6. https://doi.org/10.1097/00007632-199504000-00012

106. Lankhorst GJ, van de Stadt RJ, van der Korst JK (1985) The natural history of idiopathic low back pain. A three-year followup study of spinal motion, pain and functional capacity. Scand J Rehabil Med 17(1):1-4

107. Patrick LE, Altmaier EM, Found EM (2004) Long-term outcomes in multidisciplinary treatment of chronic low back pain: results of a 13-year follow-up. Spine (Phila Pa 1976) 29(8):8505. https://doi.org/10.1097/00007632-200404150-00006

108. Peng B, Fu X, Pang X et al (2012) Prospective clinical study on natural history of discogenic low back pain at 4 years of followup. Pain Phys 15(6):525-532

109. Raak R, Wikblad K, Raak A Sr et al (2002) Catastrophizing and health-related quality of life: a 6-year follow-up of patients with chronic low back pain. Rehabil Nurs 27(3):110-116. https://doi. org/10.1002/j.2048-7940.2002.tb01999.x

110. Rantonen J, Karppinen VA et al (2018) Effectiveness of three interventions for secondary prevention of low back pain in the occupational health setting - a randomised controlled trial with a natural course control. BMC Public Health 18(1):598. https:// doi.org/10.1186/s12889-018-5476-8

111. Rasmussen-Barr E, Ang B, Arvidsson I et al (2009) Graded exercise for recurrent low-back pain: a randomized, controlled trial with 6-, 12-, and 36-month follow-ups. Spine (Phila Pa 1976) 34(3):221-8. https://doi.org/10.1097/brs.0b013e318191e7cb

112. Rhyne AL, Smith SE, Wood KE et al (1995) Outcome of unoperated discogram-positive low back pain. Spine (Phila Pa 1976) 20(18):1997-2000. https://doi.org/10.1097/00007632-19950 9150-00007

113. Udby PM, Bendix T, Ohrt-Nissen S et al (2019) Modic changes are not associated with long-term pain and disability: a cohort study with 13-year follow-up. Spine (Phila Pa 1976) 44(17):1186-92. https://doi.org/10.1097/brs.0000000000003051

114. Van Hoof W, O'Sullivan K, Verschueren S et al (2021) Evaluation of absenteeism, pain, and disability in nurses with persistent low back pain following cognitive functional therapy: a case series pilot study with 3 -year follow-up. Phys Ther 101(1):pzaa164. https://doi.org/10.1093/ptj/pzaa164

115. Vibe Fersum K, Smith A, Kvale A et al (2019) Cognitive functional therapy in patients with non-specific chronic low back 
pain - a randomized controlled trial 3-year follow-up. Eur J Pain 23(8):1416-1424. https://doi.org/10.1002/ejp.1399

116. Brox JI, Nygaard OP, Holm I et al (2010) Four-year follow-up of surgical versus non-surgical therapy for chronic low back pain. Ann Rheum Dis 69(9):1643-1648. https://doi.org/10.1136/ard. 2009.108902

117. Froholdt A, Holm I, Keller A et al (2011) No difference in longterm trunk muscle strength, cross-sectional area, and density in patients with chronic low back pain 7 to 11 years after lumbar fusion versus cognitive intervention and exercises. Spine $\mathrm{J}$ 11(8):718-725. https://doi.org/10.1016/j.spinee.2011.06.004

118. Froholdt A, Reikeraas O, Holm I et al (2012) No difference in 9-year outcome in CLBP patients randomized to lumbar fusion versus cognitive intervention and exercises. Eur Spine $\mathbf{J}$ 21(12):2531-2538. https://doi.org/10.1007/s00586-012-2382-0

119. Furunes H, Storheim K, Brox JI et al (2017) Total disc replacement versus multidisciplinary rehabilitation in patients with chronic low back pain and degenerative discs: 8-year follow-up of a randomized controlled multicenter trial. Spine J 17(10):14801488. https://doi.org/10.1016/j.spinee.2017.05.011

120. Hedlund R, Johansson C, Hägg O et al (2016) The long-term outcome of lumbar fusion in the Swedish lumbar spine study. Spine J 16(5):579-587. https://doi.org/10.1016/j.spinee.2015.08. 065

121. Kleimeyer JP, Cheng I, Alamin TF et al (2018) Selective anterior lumbar interbody fusion for low back pain associated with degenerative disc disease versus nonsurgical management. Spine (Phila Pa 1976) 43(19):1372-80. https://doi.org/10.1097/brs. 0000000000002630

122. Axén I, Leboeuf-Yde C (2013) Trajectories of low back pain. Best Pract Res Clin Rheumatol 27(5):601-612. https://doi.org/ 10.1016/j.berh.2013.10.004

123. Kongsted A, Kent P, Axén I (2016) What have we learned from ten years of trajectory research in low back pain? BMC Musculoskelet Disord 17:220. https://doi.org/10.1186/s12891-016-1071-2

124. Dutmer AL, Schiphorst Preuper HR, Stewart RE et al (2020) Trajectories of disability and low back pain impact: 2-year follow-up of the groningen spine cohort. Spine (Phila Pa 1976) 45(23):1649-60. https://doi.org/10.1097/brs.0000000000003647

125. Froud R, Patel S, Rajendran D et al (2016) A systematic review of outcome measures use, analytical approaches, reporting methods, and publication volume by year in low back pain trials published between 1980 and 2012: respice, adspice, et prospice. PLoS ONE 11(10):E0164573. https://doi.org/10.1371/journal. pone. 0164573

126. Deyo RA, Battie M, Beurskens AJ et al (1998) Outcome measures for low back pain research. A proposal for standardized use. Spine (Phila Pa 1976) 23(18):2003-13. https://doi.org/10.1097/ 00007632-199809150-00018

127. Froud R, Ellard D, Patel S et al (2015) Primary outcome measure use in back pain trials may need radical reassessment. BMC Musculoskelet Disord 16:88. https://doi.org/10.1186/ s12891-015-0534-1

128. Chiarotto A, Boers M, Deyo RA et al (2018) Core outcome measurement instruments for clinical trials in nonspecific low back pain. Pain 159(3):481-495. https://doi.org/10.1097/j.pain.00000 00000001117

129. Artus M, van der Windt DA, Jordan KP et al (2010) Low back pain symptoms show a similar pattern of improvement following a wide range of primary care treatments: a systematic review of randomized clinical trials. Rheumathology (Oxford) 49(12):2346-2356. https://doi.org/10.1093/rheumatology/ keq245

130. Pengel LHM, Herbert RD, Maher CG et al (2003) Acute low back pain: systematic review of its prognosis. BMJ 327(7410):323. https://doi.org/10.1136/bmj.327.7410.323

131. Morton V, Torgerson DJ (2005) Regression to the mean: treatment effect without the intervention. J Eval Clin Pract 11(1):5965. https://doi.org/10.1111/j.1365-2753.2004.00505.x

132. Sauerland S, Lefering R, Neugebauer EAM (2002) Retrospective clinical studies in surgery: potentials and pitfalls. J Hand Surg Br 27(2):117-121. https://doi.org/10.1054/jhsb.2001.0703

133. Hanson B, Kopjar B (2005) Clinical studies in spinal surgery. Eur Spine J 14(8):721-725. https://doi.org/10.1007/ s00586-005-0926-2

134. Campbell PG, Malone J, Yadla S et al (2011) Comparison of ICD-9-based, retrospective, and prospective assessments of perioperative complications: assessment of accuracy in reporting. J Neurosurg Spine 14(1):16-22. https://doi.org/10.3171/2010.9. spine 10151

135. Willems PC, Staal JB, Walenkamp GHIM et al (2013) Spinal fusion for chronic low back pain: systematic review on the accuracy of tests for patient selection. Spine J 13(2):99-109. https:// doi.org/10.1016/j.spinee.2012.10.001

136. Koes BW, van Tulder MW, Ostelo R et al (2001) Clinical guidelines for the management of low back pain in primary care: an international comparison. Spine (Phila Pa 1976) 26(22):2504-13. https://doi.org/10.1097/00007632-200111150-00022

137. Willems P, de Bie R, Oner C et al (2011) Clinical decision making in spinal fusion for chronic low back pain. Results of a nationwide survey among spine surgeons. BMJ Open 1(2):E000391. https://doi.org/10.1136/bmjopen-2011-000391

138. Itz CJ, Willems PC, Zeilstra DJ et al (2016) Dutch multidisciplinary guideline for invasive treatment of pain syndromes of the lumbosacral spine. Pain Pract 16(1):90-110. https://doi.org/10. 1111/papr.12318

139. Dewitte V, de Pauw R, De Meulemeester R et al (2018) Clinical classification criteria for nonspecific low back pain: a Delphisurvey of clinical experts. Musculoskelet Sci Pract 34:66-76. https://doi.org/10.1016/j.msksp.2018.01.002

140. Amundsen PA, Evans DW, Rajendran D et al (2018) Inclusion and exclusion criteria used in non-specific low back pain trials: a review of randomised controlled trials published between 2006 and 2012. BMC Musculoskelet Disord 19(1):113. https://doi.org/ 10.1186/s12891-018-2034-6

141. Wang R, Weng L, Peng M et al (2020) Exercise for low back pain: a bibliometric analysis of global research from 1980 to 2018. J Rehabil Med 52(4):jrm00052. https://doi.org/10.2340/ 16501977-2674

142. Hoy DG, Smith E, Cross M et al (2015) Reflecting on the global burden of musculoskeletal conditions: lessons learnt from the global burden of disease 2010 study and the next steps forward. Ann Rheum Dis 74(1):4-7. https://doi.org/10.1136/annrh eumdis-2014-205393

Publisher's Note Springer Nature remains neutral with regard to jurisdictional claims in published maps and institutional affiliations. 